\title{
Kraniofacialne rekonstrukcije pri otrocih s kraniosinostozo
}

\section{Craniofacial Reconstructions in Children with Craniosynostosis}

Peter Spazzapan, Miha Kočar, Andreja Eberlinc, Tomaž Velnar

\section{Izvleček}

Izhodišče. Kraniosinostoze so redke prirojene bolezni lobanje, ki nastanejo ob prezgodnji zakostenitvi enega ali več lobanjskih šivov. Ker možgani ne morejo več prosto rasti, pride do deformacij lobanje, ki lahko dolgoročno povzročijo znotrajlobanjsko hipertenzijo in kognitivni zaostanek.

Preiskovanci in metode. V Enoti za otroško nevrokirurgijo UKC Ljubljana smo pregledali vse otroke, ki so bili od junija 2015 do septembra 2020 zdravljeni zaradi kraniosinostoze ( $\mathrm{N}=71$; starost 12,8 let, obdobje spremljanja 2,7 let). Zbrali smo naslednje podatke: prizadet šiv, sindromska bolezen, hidrocefalus, Chiarijeva malformacija, povišan znotrajlobanjski tlak, starost ob operaciji, kirurška tehnika, potreba po več operacijah in zapleti kirurškega zdravljenja.

Rezultati. Sagitalnih je bilo 54,9\%, 25,3\% metopičnih, $14 \%$ koronarnih enostranskih, 1,4 \% koronarnih obojestranskih in 1,4 \% lambdoidnih enostranskih. V 2,8 \% primerov je bilo prizadetih več lobanjskih šivov. Sindromskih primerov je bilo $7 \%$. Skupaj smo opravili 74 posegov: $40,5 \%$ frontoorbitalno podaljšanje, 32,4\% biparietalno remodeliranje, 22,9\% remodeliranje celotnega svoda, 2,7 \% posteriorno distrakcijo in 1,3\% posteriorno ekspanzijo.

Zaključki. Zdravljenje kraniosinostoz zahteva multidisciplinarni nevrokirurški, maksilofacialni in oralnokirurški pristop ter posege plastične in rekonstruktivne kirurgije. Zdravljenje kraniosinostoz je izključno kirurško. Poseg ni potreben le v kozmetične namene, temveč predvsem zato, da možganom omogočimo normalno rast.

Ključne besede: kraniosinostoza, znotrajlobanjska hipertenzija, apneja, hidrocefalus, Chiarijeva malformacija. 


\section{Uvod}

Kraniosinostoze so redke bolezni otrok, ki nastanejo ob prezgodnji zakostenitvi enega ali več lobanjskih šivov. Zato se otroška lobanja ne more več prosto razvijati v vse smeri, hitro rastoči možgani pa iščejo prostor drugje oziroma tam, kjer je manj rezistence. Nastanejo deformacije glave, ki so značilne glede na zakosteneli šiv. Poznamo sindromske in nesindromske kraniosinostoze. Med nesindromskimi so najbolj pogoste skafocefalija, trigonocefalija in anteriorna plagiocefalija, bolj redki sta brahicefalija in posteriorna plagiocefalija. Sindromske kraniosinostoze so bolj kompleksna stanja, pri katerih je običajno zakostenelih več šivov, navadno pa so pridruženi tudi znotrajlobanjska hipertenzija, hidrocefalus in Chiarijeva malformacija (1). Zdravljenje kraniosinostoz je kirurško in zahteva kompleksno remodeliranje deformiranih delov lobanje (2). Kirurški poseg opravimo pri različnih starostih, in sicer glede na prizadeti šiv ter glede na nevrološko in splošno stanje otroka. $V$ večini poseg izvedemo v prvih 12 mesecih življenja. S kirurškim zdravljenjem želimo možganom omogočiti normalne pogoje za rast in razvoj. Estetski razlog je sekundarnega pomena.

\section{Klinična slika posameznih kraniosinostoz}

\section{Skafocefalija}

Skafocefalija nastane zaradi prezgodnje zakostenitve sagitalnega šiva (Slika 2), ki se v normalnih pogojih zapre med prvim in drugim letom starosti. S pojavnostjo 1/5000 rojstev je najbolj pogosta nesindromska kraniosinostoza in bolj pogosta pri moških kot pri ženskah. Za skafocefalijo so značilne podolgovata oblika glave, protruzija čela in zatilja ter ozka bitemporalna in biparietalna razdalja. Pri skafocefaliji ni asimetrije obraza, orbit in

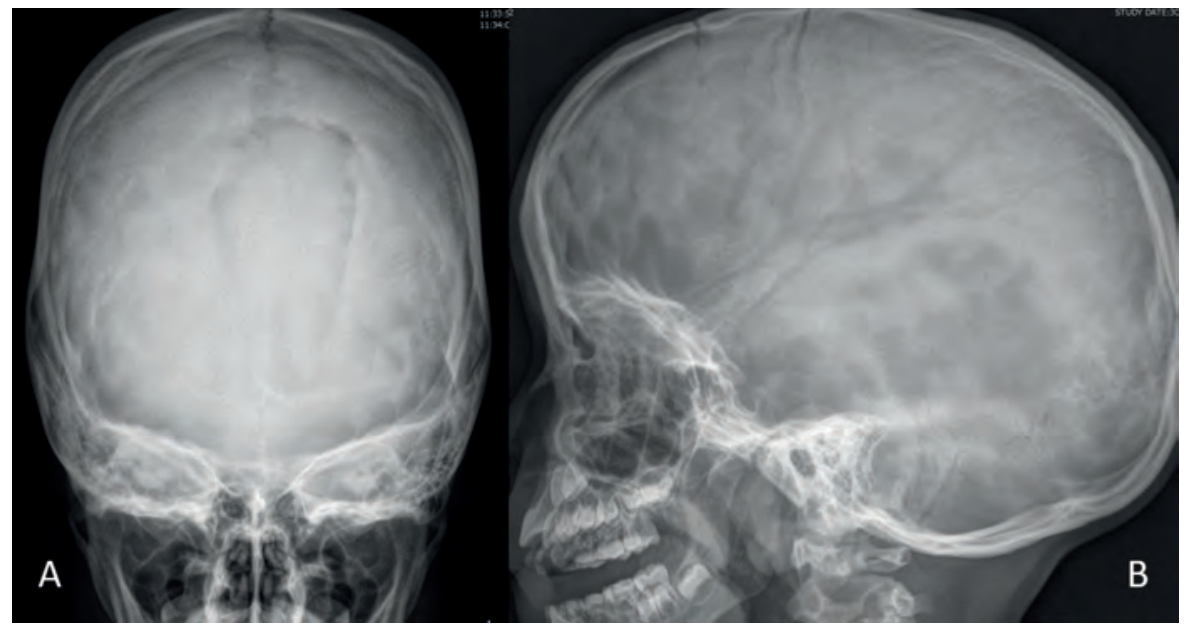

SLIKA 1. LOBANJA Z IZGLEDOM TOLČENEGA BAKRA (ANGL. COPPER BEATEN) NA RTG SLIKAH (A IN B) JE ZNAK POVIŠANEGA ZNOTRAJLOBANJSKEGA TLAKA, KI LAHKO NASTANE ZARADI KRANIOSINOSTOZE. GRE ZA ZNAKE, KI JIH MOŽGANSKE VIJUGE OB POVIŠANEM ZNOTRAJLOBANJSKEM TLAKU PUSTIJO NA LOBANJSKI LAMINI INTERNI.

FIGURE 1. "COPPER BEATEN" APPEARANCE OF THE SKULL ON X-RAY IMAGING (A AND B) INDICATES RAISED INTRACRANIAL PRESSURE, WHICH CAN BE CAUSED BY CRANIOSYNOSTOSIS. THESE ARE SIGNS THAT THE CEREBRAL GYRI LEAVE ON THE INTERNAL LAMINA IN RAISED INTRACRANIAL PRESSURE.

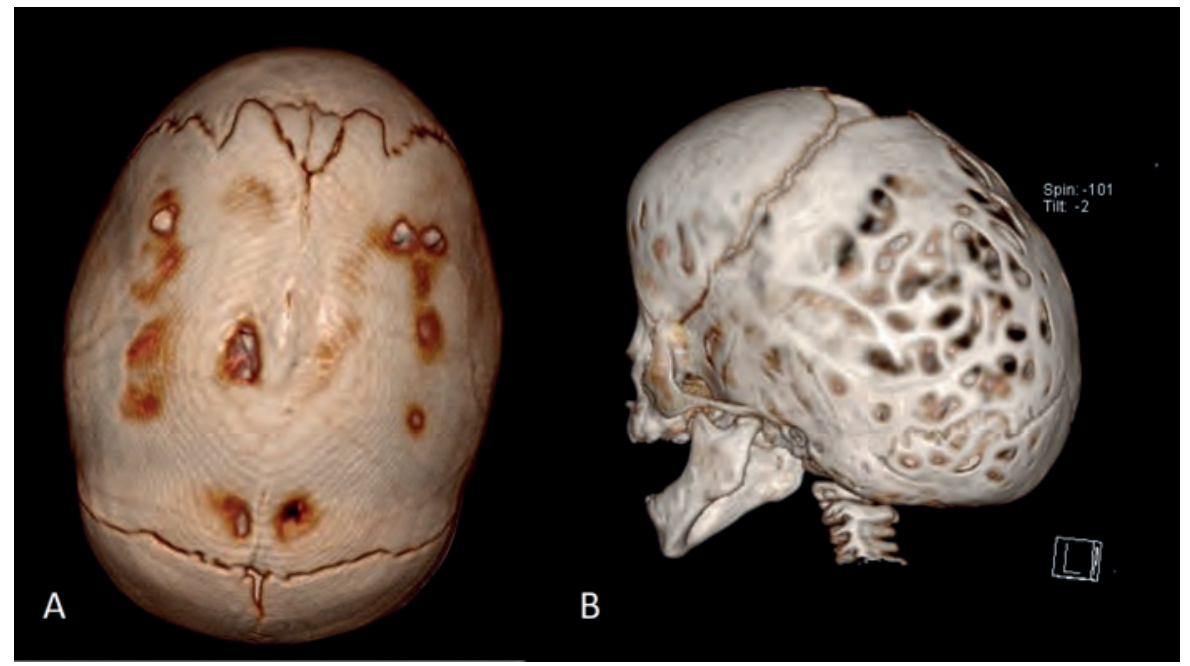

SLIKA 2. CT IZGLED DVEH PRIMEROV SINOSTOZE SAGITALNEGA ŠIVA. GLAVA DOBI PODOLGOVATO IN OZKO OBLIKO (A) Z IZRAZITIM FRONTALNIM IZBOČENJEM (B).

FIGURE 2. CT SCANS OF TWO CASES OF SAGITTAL CRANIOSYNOSTOSIS. THE HEAD SHAPE BECOMES ELONGATED AND NARROWED (A), WITH CLEARLY RECOGNISABLE FRONTAL BOSSING (B). 


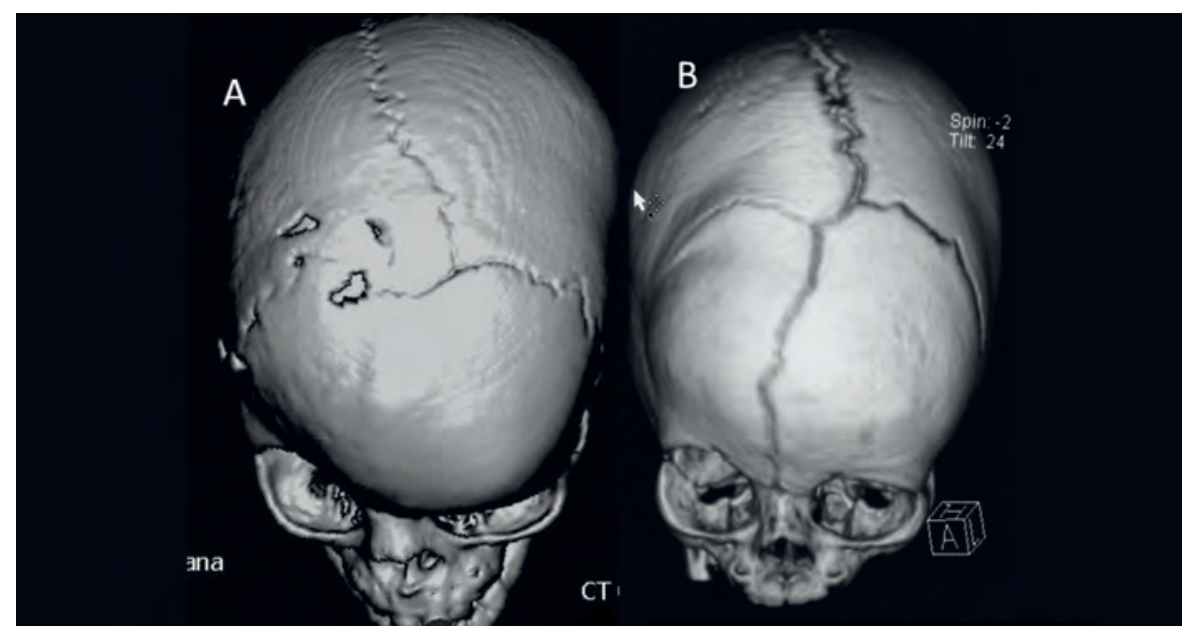

SLIKA 3. CT IZGLED KRANIOSINOSTOZE METOPIČNEGA ŠIVA. ČELO POSTANE TRIKOTNE OBLIKE (A), ZNAČILEN JE TUDI HIPOTELORIZEM OZIROMA ZMANJŠANA RAZDALJA MED NOTRANJIMA OČESNIMA KOTOMA (B).

FIGURE 3. CT APPEARANCE OF CRANIOSYNOSTOSIS OF THE METOPIC SUTURE: THE FOREHEAD BECOMES TRIANGULAR (A). HYPOTELORISM IS ALSO A TYPICAL FINDING, INDICATING A DECREASED DISTANCE BETWEEN THE TWO MEDIAL CANTHI.

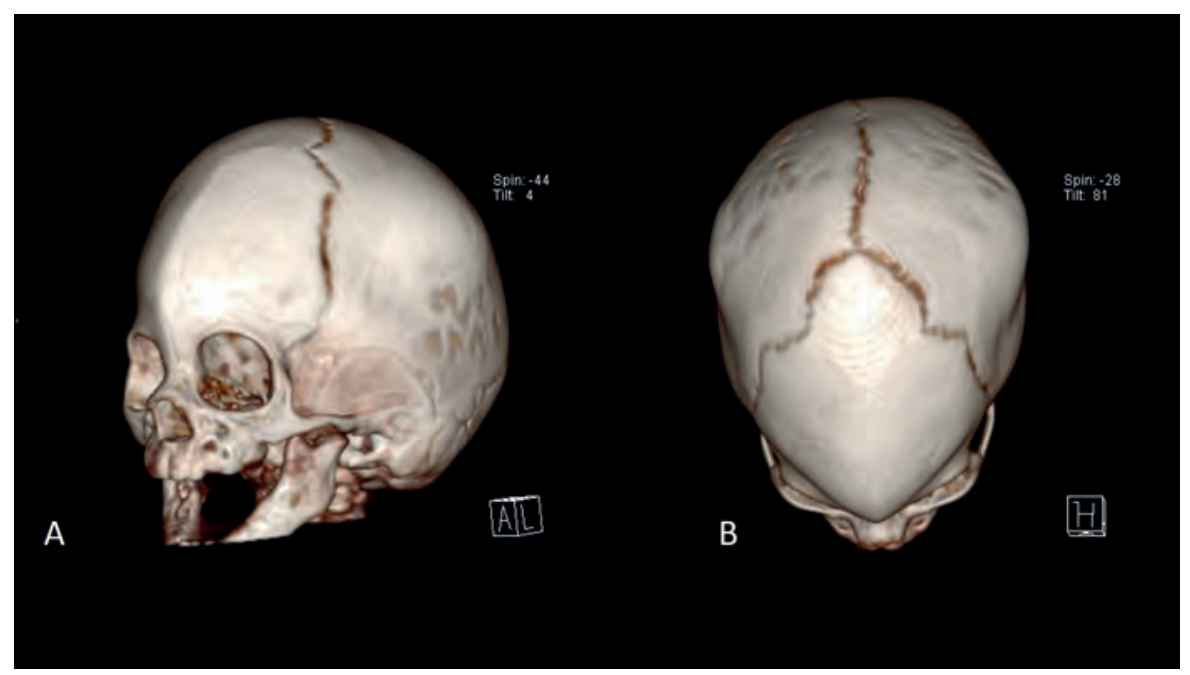

SLIKA 4. CT IZGLED KRANIOSINOSTOZE KORONARNEGA ŠIVA. GLAVA POSTANE IZRAZITO ASIMETRIČNA (A IN B), UKRIVIJO SE TUDI ORBITI, NOSNI KOREN IN OS OBRAZA.

FIGURE 4. CT APPEARANCE OF UNILATERAL CORONAL CRANIOSYNOSTOSIS: THE HEAD BECOMES MARKEDLY ASYMMETRICAL (A AND B). THE ORBITS, NOSE AND FACIAL AXIS ARE DEFORMED. možganske baze. Ob ustreznem in pravočasnem zdravljenju je tveganje nevrološko-kognitivne prizadetosti zelo majhno. Blago obliko opisujejo pri 0-9 \% (3).

\section{Trigonocefalija}

Trigonocefalija nastane zaradi prezgodnje zakostenitve metopičnega šiva (Slika 3), ki ločuje levo in desno frontalno lusko ter se normalno zapre že med 4 . in 9. mesecem starosti. Trigonocefalija je bila nekoč tretja najbolj pogosta kraniosinostoza, v zadnjih desetih letih pa v Evropi njena pojavnost narašča, verjetno $v$ povezavi s spremembami okolja, prehrane in jemanjem zdravil (4). Dokazana je povezava med trigonocefalijo in valproatom ter ščitničnim nadomestnim zdravljenjem (4). Klinični znaki trigonocefalije so izbočena mediana linija čela, ozka bitemporalna razdalja, kratka bizigomatska razdalja, anteriorno pomaknjen koronarni šiv, posteriorno pomaknjen supraorbitalni lok, hipotelorizem in parietookcipitalna razširitev. Možnost nevrološko-kognitivne prizadetosti je pri trigonocefaliji večja kot pri ostalih kraniosinostozah, saj je kljub ustreznemu zdravljenju v $30 \%$ primerov prisoten blag do zmeren kognitivni in motorični zaostanek $[4,5]$. Zato je pri trigonocefaliji priporočljivo tudi magnetnoresonančno (MRI) slikanje glave za izključitev možganskih anomalij (hipoplazija kaloznega korpusa, Chiarijeva malformacija, cavum septi pellucidi).

\section{Anteriorna plagiocefalija}

Anteriorna plagiocefalija je posledica kraniosinostoze enega od dveh koronarnih šivov (Slika 4). Gre za kompleksno nesindromsko kraniosinostozo, saj deformacija sega tudi v možgansko bazo in viscerokranium. Predstavlja 13-16 \% vseh kraniosinostoz (3) s pojavnostjo 1/10.000. Kraniofacialne značilnosti anteriorne plagiocefalije so vzravnano ipsilateralno čelo, izbočenje ipsilateralne temporalne luske, izbočenje kontralateralnega čela, ipsilateral- 
ni odklon nosnega korena, anteriorni pomik ipsilateralnega ušesa, znižana kontralateralna orbita, kratka ipsilateralna sprednja kotanja, ozek sfenopetrozni kot, ozka ipsilateralna orbita in kratka ipsilateralna mandibula. Pomemben radiološki znak je ipsilateralna, t. i. harlekinska deformacija (Slika 5) oziroma superiorno pomaknjeno sfenoidno krilo. Tudi pri anteriorni plagiocefaliji je tveganje nevrološko-kognitivne prizadetosti veliko, saj kljub zdravljenju prizadene do $30 \%$ otrok (5).

\section{Brahicefalija}

Brahicefalija je ena izmed redkih oblik nesindromskih kraniosinostoz, saj predstavlja le $5 \%$ primerov (3). Nastane zaradi sinostoze obojestranskega koronarnega šiva (Slika 6). Kraniofacialne značilnosti brahicefalije so zmanjšan antero-posteriorni obseg glave, povečana latero-lateralni in infero-superiorni obseg glave, sploščenost zatilja in čela, anteriorno pomaknjen verteks, hipertelorizem, posteriorno pomaknjen supraorbitalni lok, obojestranska bitemporalna protruzija in kratka sprednja lobanjska kotanja. Na rentgenskih slikah je vidna obojestranska harlekinska deformacija. Obojestranska koronarna sinostoza se pogosto pojavi pri kraniofacialnih sindromih, kot so Crouzonov, Apertov, Pfeifferjev in Saethre -Chotzenov sindrom, zato moramo razlikovati med sindromskimi in nesindromskimi primeri. Možnost nevrološke in kognitivne prizadetosti je pri brahicefaliji 20-40 \% (5).

\section{Posteriorna plagiocefalija}

Posteriorna plagiocefalija je najbolj redka kraniosinostoza, saj predstavlja samo 2-3\% primerov. Sinostotični šiv je $v$ tem primeru monolateralni lambdoidni šiv (Slika 7). Tudi v tem primeru gre za kompleksno deformacijo nevrokraniuma in tudi viscerokraniuma. Kraniofacialne značilnosti so ipsilateralna sploščenost zatilja, ipsilateralna protruzija mastoida, protrudirano kontralateralno zatilje, trapezoidna

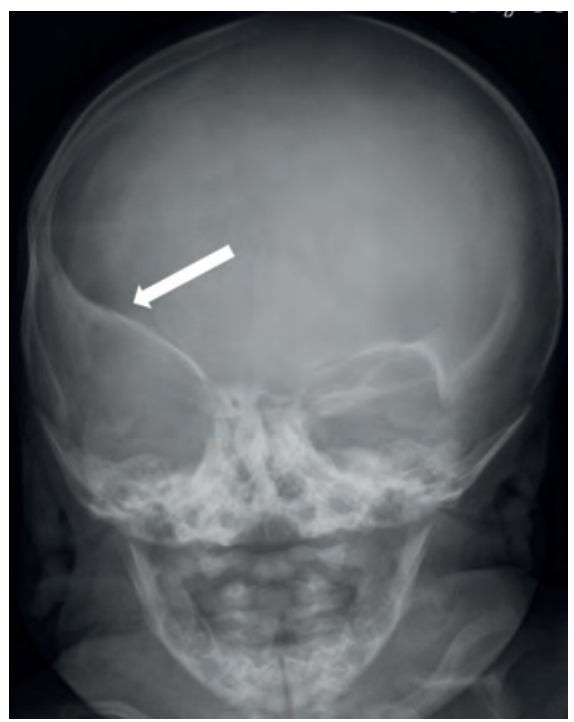

SLIKA 5. "HARLEQUIN" DEFORMACIJA OZIROMA NAVZGOR POMAKNJENO SFENOIDNO KRILO (BELA PUŠČICA).

FIGURE 5. THE WHITE ARROW SHOWS THE HARLEQUIN DEFORMATION, WHICH INDICATES THE UPWARD DISPLACEMENT OF THE SPHENOID WING.

\begin{tabular}{lcc} 
& Število & Delež (\%) \\
\hline Prizadeti šiv & 39 & \\
\hline sagitalni & 18 & 54,9 \\
\hline metopični & 10 & 25,3 \\
\hline koronarni enostransko & 1 & 14,1 \\
\hline korornarni obojestransko & 1 & 1,4 \\
\hline lambdoidni & 2 & 1,4 \\
\hline več šivov & 71 & 2,8 \\
\hline Skupaj & 5 & 100 \\
\hline Sindromska bolezen & 7 & 7 \\
\hline Povišan znotrajlobanjski tlak & 1 & 9,9 \\
\hline Hidrocefalus & 2 & 1,4 \\
\hline Chiarijeva malformacija & 2,8 \\
\hline
\end{tabular}

TABELA 1. KLINIČNE ZNAČILNOSTI OTROK, VKLJUČENIH V RAZISKAVO.

TABLE 1. CLINICAL CHARACTERISTICS OF THE 71 CHILDREN INCLUDED IN THE STUDY. 


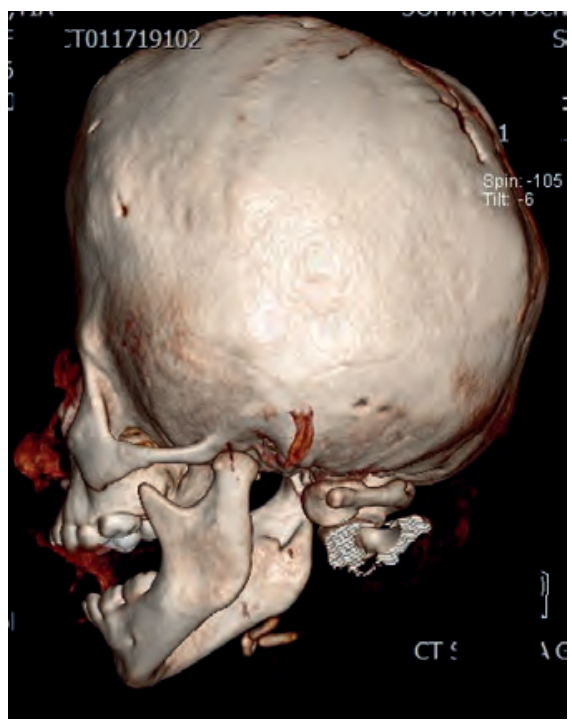

SLIKA 6. BRAHICEFALIJA KOT POSLEDICA BIKORONARNE KRANIOSINOSTOZE. ZNAČILNI SO KRATKA ANTEROPOSTERIORNA OS GLAVE, RETRAKCIJA SUPRAORBITALNEGA LOKA IN FRONTALNO IZBOČENJE.

FIGURE 6. BRACHYCEPHALY IS THE CONSEQUENCE OF BILATERAL CORONAL CRANIOSYNOSTOSIS. CHARACTERISTICS OF THIS CONDITION ARE A SHORT ANTEROPOSTERIOR HEAD DIAMETER, RETRACTION OF THE SUPRAORBITAL ARCH AND FRONTAL BOSSING.

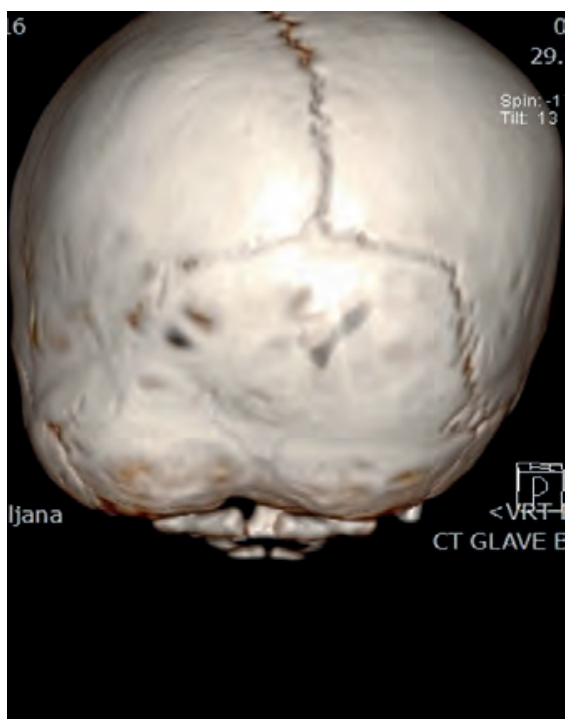

SLIKA 7. ENOSTRANSKA LAMBDOIDNA KRANIO SINOSTOZA JE NAJBOLJ REDKA IN POVZROČI ASIMETRIJO CELOTNEGA LOBANJSKEGA SVODA TER RETRAKCIJO IPSILATERALNEGA UŠESA.

FIGURE 7. UNILATERAL LAMBDOID CRANIOSYNOSTOSIS IS THE RAREST AND CAUSES ASYMMETRY OF THE WHOLE CRANIAL VAULT AND RETRACTION OF THE IPSILATERAL EAR.

\begin{tabular}{lcccc} 
& Število & Delež (\%) & Srednja starost (meseci) \\
\hline Kirurška tehnika & 30 & 40,5 & 16,4 \\
\hline frontoorbitalno podaljšanje & 24 & 32,4 & \\
\hline biparietalno remodeliranje & 17 & 22,9 & 5,1 \\
\hline remodeliranje celega svoda & 2 & 2,7 & 11,3 \\
\hline posteriorna distrakcija & 1 & 1,3 & \\
\hline posteriorna ekspanzija & 74 & 100 & 23,6 \\
\hline Skupaj & 3 & 4 & 12,8 \\
\hline potreba po drugi operaciji & & &
\end{tabular}

TABELA 2. PODATKI O KIRURŠKEM ZDRAVLJENJU.

TABLE 2. DATA ON THE SURGICAL TREATMENT.

oblika glave s ptičje perspektive in posteriorno pomaknjeno ipsilateralno uho. Pri sindromskih oblikah je prizadetost lambdoidnega šiva večinoma obojestranska.

Posteriorno plagiocefalijo moramo razlikovati od deformacijske plagiocefalije, ki ni kraniosinostotična bolezen. Gre za zelo pogosto deformacijo, ki se pojavi pri 4-20\% (6) vseh novorojenčkov. Noben šiv ni zakostenel in glava ima s ptičje perspektive značilno obliko paralelograma. Pri deformacijski plagiocefaliji so indicirani le konzervativni ukrepi: ležanje na kontralateralni strani in morebitna uporaba čelade (6). Zdravljenje ni kirurško, razen $v$ redkih primerih, ko se deformacija kljub konzervativnim ukrepom ne reši in ko si starši izrazito želijo, da se deformacija popravi v estetke namene. Radiološke diagnostične preiskave niso potrebne, saj je glava v obliki paralelograma dovolj jasen znak za izključitev kraniosinostoze. Ob dvomu moramo opraviti navadno ultrazvočno preiskavo (UZ) ali računalniško tomografijo (CT) glave za potrditev odprtosti obeh lambdoidnih šivov.

\section{Preiskovanci in metode}

V Enoti za otroško nevrokirurgijo UKC Ljubljana smo pregledali vse otroke, ki so bili obravnavani zaradi kraniosinostoze v obdobju od junija 2015 do septembra 2020. Spremljali smo naslednje parametre: prizadet šiv, sindromska bolezen, hidrocefalus, Chiarijeva malformacija, povišan znotrajlobanjski tlak, starost ob operaciji, kirurška tehnika, potreba po več operacijah in zapleti kirurškega zdravljenja. Vključeni so bili otroci, ki so bili prvič obravnavani po juniju 2015, ko je bil v UKC Ljubljana ustanovljen multidisciplinarni konzilij za kraniofacialne malfomacije, ki ga sestavljajo nevrokirurgi, maksilofacialni kirurgi, plastični in rekonstruktivni kirurgi, pediatri nevrologi, neonatologi in otorinolaringologi. 
Vsi otroci, vključeni v raziskavo, so pred kirurškim zdravljenjem opravili klinični pregled v nevrokirurški ambulanti na Pediatrični kliniki UKC Ljubljana. Diagnozo so v vseh primerih potrdili s slikovnim diagnosticiranjem (UZ, CT ali MRI). Sledila je še predstavitev na multidisciplinarnem konziliju.

Kirurške tehnike so se razlikovale glede na prizadeti lobanjski šiv. Uporabljene tehnike so bile: frontoorbitalno podaljšanje (angl. frontoorbital advancement, FOA), biparietalno remodeliranje (angl. biparietal remodelling), remodeliranje celotnega svoda (angl. total cranial vault remodelling), posteriorna distrakcija (angl. posterior distraction) in posteriorna ekspanzija (angl. posterior expansion).

\section{Rezultati}

Od junija 2015 do septembra 2020 smo obravnavali in kirurško zdravili 71 otrok s kraniosinostozo. Ker se v Sloveniji na leto rodi 20.000 otrok, je pojavnost kraniosinostoz v Sloveniji 1/1500 rojstev.

Srednje obdobje spremljanja otrok po operaciji je bilo 2 leti in 7 mesecev. Bolniki so bili v 56 primerih $(78,9 \%)$ moškega spola in v 15 primerih $(21,1$ \%) ženskega spola. Splošne predoperativne podatke o otrocih prikazujemo $\checkmark$ Tabeli 1. Prizadeti šivi so bili: sagitalni v 39 primerih (54,9\%), metopični v 18 primerih $(25,3 \%)$, koronarni enostransko v 10 primerih (14\%), koronarni obojestransko v enem primeru $(1,4 \%)$ in lambdoidni enostransko $v$ enem primeru $(1,4 \%)$. Več šivov je bilo prezgodaj zaraščenih v dveh primerih $(2,8 \%)$, oba primera sta bila sindromska. Sindromskih primerov je bilo 5 (7 \%): dva primera Apertovega sindroma, en primer Muenkovega sindroma, en primer frontonazoorbitalnega sindroma in en PTEN hamartoma tumorski sindrom.

$\checkmark$ vseh primerih je bilo zdravljenje kirurško (Tabela 2). Skupaj smo opravili 74 posegov, od tega v 30 primerih $(40,5 \%)$ frontoorbitalno podaljšanje
(FOA), 24 primerih (32,4\%) biparietalno remodeliranje, 17 primerih $(22,9 \%)$ remodeliranje celotnega svoda, $v$ dveh primerih $(2,7 \%)$ posteriorno distrakcijo in v enem primeru $(1,3 \%)$ posteriorno ekspanzijo.

Srednja starost ob prvem posegu je bila 12,8 meseca (razpon: 3 meseci do 10 let). Otroci s skafocefalijo so bili operirani v srednji starosti 5,1 meseca, $v$ dveh primerih je pa bil poseg zaradi nepostavljene diagnoze v obdobju zgodnjega otroštva opravljen pri starejših otrocih (10 in 8 let). Pri otrocih $\mathrm{s}$ sinostozo metopičnega ali koronarnih šivov smo FOA opravili pri srednji starosti 16,4 meseca. Tri posteriorne ekspanzije smo izvedli pri srednji starosti 11,3 meseca.

Drugo operacijo smo $v$ času raziskave opravili v treh primerih. $V$ enem primeru smo izvedli FOA po posteriorni distrakciji pri otroku z Apertovim sindromom. $V$ drugem primeru smo opravili remodeliranje celotnega svoda zaradi vztrajajoče skafocefalne oblike glave po prvem biparietalnem remodeliranju. $V$ tretjem primeru smo zaradi znotrajlobanjske hipertenzije po korekciji trigonocefalije izvedli biparietalno ekspanzijo lobanjskega svoda.

$V$ sedmih primerih so bili prisotni znaki povišanega znotrajlobanjskega tla$\mathrm{ka}$, in sicer zastojna papila, t. i. copper beaten videz lobanje (znak prstnih odtisov oz. izgled tolčenega bakra na rentgenskem posnetku lobanje) (Slika 1) in intraoperativna najdba vijugaste površine lamine interne. Vsi bolniki s temi znaki so bili pri posegu starejši od dveh let, kar dokazuje, da znotrajlobanjska hipertenzija postopno postaja vse bolj izrazita. Dihanje ni bilo problematično $v$ nobenem primeru in $v$ nobenem primeru tudi nismo dokazali centralne apneje. Eksoftalmus je bil prisoten $v$ blagi obliki v dveh primerih Apertovega sindroma, a ukrepanje za reševanje roženice ni bilo potrebno. Hidrocefalus smo prepoznali $v$ enem samem primeru, a ne $v$ povezavi s kraniosinostozo, temveč $v$ obliki posthemoragičnega hidrocefalusa nedonošenega otroka. Chiarijeva malformacija je bila v brezsimptomni obliki prisotna v dveh primerih, kraniocervikalna dekompresija pa ni bila indicirana. Kirurški zapleti so se pojavili v dveh primerih. Težave s celjenjem rane smo ugotovili v enem samem primeru, pri katerem smo morali dehiscenco prekriti z rotacijskim kožnim režnjem. $\checkmark$ enem primeru je prišlo do postoperativnega, po Gramu negativnega celulitisa na glavi in obrazu.

Splošna pogostost zapletov v naši seriji bolnikov je bila torej $2,8 \%$.

\section{Razpravljanje}

Lobanja vretenčarjev je sestavljena iz nevrokraniuma, ki obdaja in ščiti možgane, in viscerokraniuma, ki tvori obraz. Nevrokranium sestavljata hrustančni nevrokranium, ki tvori možgansko bazo, in vezivni nevrokranium, ki tvori kalvarijo. Pri otrocih do tretjega leta starosti lahko možgani nemoteno rastejo in ob tem ostanejo primerno mehansko zaščiteni. To omogoča rast lobanjskih kosti, ki se med seboj stikajo in se med rastjo možganov razvijajo. Na stičiščih lobanjskih kosti se oblikujejo šivi, kjer se postopno odlaga kostno tkivo. Šivi torej delujejo kot osifikacijski centri lobanje.

O kraniosinostozah govorimo, ko se lobanjski šivi prehitro zarastejo in ne delujejo več kot osifikacijski centri. Pri kraniosinostozah se rast lobanje zaradi prehitrega zaraščanja enega šiva ali več lobanjskih šivov na tistem mestu ustavi, zato se lobanja deformira. Hitro rastoči možgani najdejo prostor za svojo hitro rast drugje, zato pride do kompenzacijske rasti v vzporedni smeri glede na prizadeti šiv in ne več v pravokotni. Klinična slika se razlikuje glede na zakosteneli šiv (3).

Kraniosinostoze so lahko izolirane ali pridružene drugim sindromom. Pojavnost ocenjujejo na $1 / 2100$ rojstev. Nesindromske kraniosinostoze pred- 
stavljajo $85 \%$ vseh primerov, sindromske pa $15 \%(1,3)$. Rezultati naše raziskave so podobni, saj je letna pojavnost nesindromskih kraniosinostoz $1 / 1500$ rojstev, sindromskih primerov pa je $7 \%$.

Med znanimi etiologijami kraniosinostoz so genetske, presnovne in hematološke bolezni, mukopolisaharidoza, teratogeni vzroki (valproična kislina, retinojska kislina), likvorska drenaža in mikrocefalija (3). Z genetskimi preiskavami so odkrili nekatere gene, ki so vpleteni v patogenezo kraniosinostoz. Geni FGFR-1, -2, -3, -4 in $T G F-1,-2,-3$ namreč kodirajo receptorje, ki so udeleženi v procesih diferenciacije, proliferacije in migracije celic lobanjskih šivov.

Glede na morfološke fenotipe je najpogostejša nesindromska sagitalna sinostoza (40-55\%), na drugem mestu je metopična sinostoza (15-30\%), sledita enostranska in obojestranska koronarna sinostoza (15-20\%). Lambdoidna sinostoza je najbolj redka (0-5\%). Zaraščenost dveh ali več šivov je redka in se večinoma pojavlja v sindromskih primerih (3). Tudi v naši seriji bolnikov so rezultati podobni. Prav tako je več otrok moškega spola $(78,9 \%)$, kar se ujema s podatki iz literature (3).

Diagnosticiranje kraniosinostoz je v začetni fazi klinično. Glede na prizadeti šiv se pojavijo značilne deformacije glavice. Dodatna klinična znaka sta palpatorni greben, ki se pojavi nad zaraščenim šivom, in odsotnost pomičnosti dveh kosti ob šivu. Končno diagnozo postavimo radiološko. Že z ultrazvočno (UZ) preiskavo glave potrdimo zakostenelost šiva, CT glave s 3D- rekonstrukcijo pa to tudi jasno prikaže. UZ in CT sta predvsem pomembna $v$ redkih primerih, pri katerih ob kliničnem pregledu ni mogoče z gotovostjo potrditi kraniosinostoze. Za izključitev prisotnosti povišanega znotrajlobanjskega tlaka je indiciran pregled očesnega ozadja. Podrobnejše podatke glede anatomije možganov dobimo z magnetnoresonančnim slikanjem (MRI), ki pa je le redko indicirano, ker veliko možganskih anomalij prepoznamo že z UZ glave. Genetske preiskave so potrebne vedno ob sumu na sindromsko kraniosinostozo.

Kraniosinostoze zdravimo izključno kirurško. Z odprtim posegom moramo sprostiti konstriktivno in deformativno težnjo, ki jo ima sinostoza na rast glave. To zahteva remodeliranje kostnih struktur nevrokraniuma in po potrebi tudi viscerokraniuma. Poseg je potreben ne le v kozmetične namene, temveč predvsem zato, da možganom omogočimo normalno rast. Starost, pri kateri opravimo kirurško sprostitev kraniosinostoze, je odvisna od prizadetega šiva, od morebitne prisotnosti hidrocefalusa ali Chiarijeve malformacije ter od sistemskega, predvsem respiratornega stanja otroka. $\mathrm{V}$ veliki večini primerov poseg opravimo $v$ prvih 12 mesecih življenja.

Kirurgija kraniosinostoz je zahtevna in ni brez zapletov, saj se po podatkih iz literature pojavijo v 2-8\% primerov (7). Smrtnost v vseh sodobnih serijah ocenjujejo na manj kot $1 \%$. Možni zapleti so dehiscenca rane, okužba, podkožni hematom ter dehiscenca dure in posledična subkutana likvorska fistula. V naši seriji smo zabeležili le eno dehiscenco rane $(1,4 \%)$ in en primer sistemske okužbe $(1,4 \%)$. Smrtnost je bila $0 \%$.

Vrednotenje uspešnosti operaciji kraniosinostoz temelji na estetskem in predvsem na funkcionalnem izidu. Estetski izid težko objektivno ocenimo. $\checkmark$ ta namen se poslužujemo predvsem izračuna kranialnega indeksa (širina lobanje/dolžina lobanje), ki je pri zdravih otrocih 76-78 \% (8). Čim bolj se vrednost kranialnega indeksa po posegu približa tem vrednostim, tem bolj ugoden je estetski izid.

Kognitivni izid ocenjujemo na podlagi nevropsiholoških testiranj, ki jih opravimo med otrokovim razvojem. Pri otrocih brez pridruženega hidrocefalusa in brez povišanega znotraj- lobanjskega tlaka so določene težave kljub operaciji prisotne v 30-50 \% (9). Najbolj izrazite so na področju usvajanja govora, pisanja in branja, čeprav je inteligenčni količnik večinoma v mejah normalnih vrednosti.

\section{Principi zdravljenja}

S kirurškim zdravljenjem kraniosinostoz želimo doseči sprostitev nevrokraniuma in možganom omogočiti normalno rast. Estetski namen je sicer pomemben, a ni primaren.

Pri načrtovanju zdravljenja otroka s kraniosinostozo moramo upoštevati, kateri šiv je prizadet, splošno in nevrološko stanje otroka ter pridružene patologije in malformacije.

$\checkmark$ veliki večini nesindromskih kraniosinostoz je dovolj, da opravimo en sam poseg remodeliranja lobanje. Hidrocefalus ali Chiarijeva malfomacija sta v teh primerih pridružena zelo redko. V sindromskih primerih so Chiarijeva malformacija, znotrajlobanjska hipertenzija in hidrocefalus bolj pogosti (1). Pogoste so tudi apneje, ki so tako centralne (vezane na Chiarijevo malformacijo) kot periferne (vezane na maksilarno hipoplazijo in zožitev zgornjih dihalnih poti). Gre torej za kompleksna klinična stanja, ki jih je potrebno razrešiti z več posegi v pravilnem časovnem sosledju. Zdravljenje takšnih otrok je dolgotrajno in multidisciplinarno.

\section{Skafocefalija}

Pri operaciji skafocefalije moramo izvesti obsežno remodeliranje celotnega vezivnega nevrokraniuma in možganom omogočiti, da prosto rastejo v vse smeri in simetrično oblikujejo lobanjo. Idealna starost za operacijo je 3-6 mesecev, saj imajo možgani po posegu dovolj rastnega potenciala, da lahko sami oblikujejo lobanjski svod. Zato pri teh operacijah ne uporabljamo osteosintetskega materiala. Opisanih kirurških tehnik je veliko, najbolj uporabne 
pa so biparietalno remodeliranje z Renierjevo tehniko (10), remodeliranje celotnega svoda (Slika 8) in endoskopsko remodeliranje (11). Endoskopsko remodeliranje ima prednost zaradi manjšega kožnega vreza in manjše izgube krvi. Pri takem posegu izvedemo samo suturektomijo sagitalnega šiva, ne pa obsežnega remodeliranja lobanjskih kosti. Zato je uspeh bolj odvisen od pooperativnega nošenja korekcijske čelade kot pa od samega primarnega kirurškega remodeliranja.

\section{Trigonocefalija}

Za korekcijo trigonocefalije je indicirano frontoorbitalno podaljšanje (FOA) $(4,12)$. Pri tem posegu preko bikoronarnega vreza dvignemo obsežen bifrontalni reženj in nato tudi supraorbitalni kostni lok (fr. bandeau). Po ustreznem remodeliranju teh dveh kostnih elementov popravljeni supraoorbitalni kostni lok z novim čelom vstavimo na svoje mesto in fiksiramo z resorptivnimi ploščicami (Slika 9). S tem želimo ustvariti vzravnano čelo, popraviti hipotelorizem in povečati bitemporalno razdaljo. Idealen čas za poseg je po 12. mesecu starosti, ko je rast možganov v veliki meri zaključena (13). Prezgodnji poseg, tj. pred devetim mesecem starosti, ni indiciran, ker bi rastoči možgani lahko naleteli na trdo, nepremično pregrado, ki jo predstavlja osteosintetski material.

\section{Anteriorna plagiocefalija}

Za korekcijo anteriorne plagiocefalije je indicirano FOA, pri katerem je podaljšanje na prizadeti, plagiocefalni strani bolj izraženo kot na neprizadeti strani (14). Cilj je vzpostavitev simetrije med levo in desno polovico lobanje, kar običajno težko dosežemo (Slika 10), ker sega asimetrija tudi v predele nevrokraniuma in viscerokraniuma, kamor kirurški poseg ne seže. S sprostitvijo sinostoze se vsekakor vzpostavijo pogoji za nemoteno nadaljnjo rast lobanje, zato se asimetrija v letih po posegu postopno popravlja.

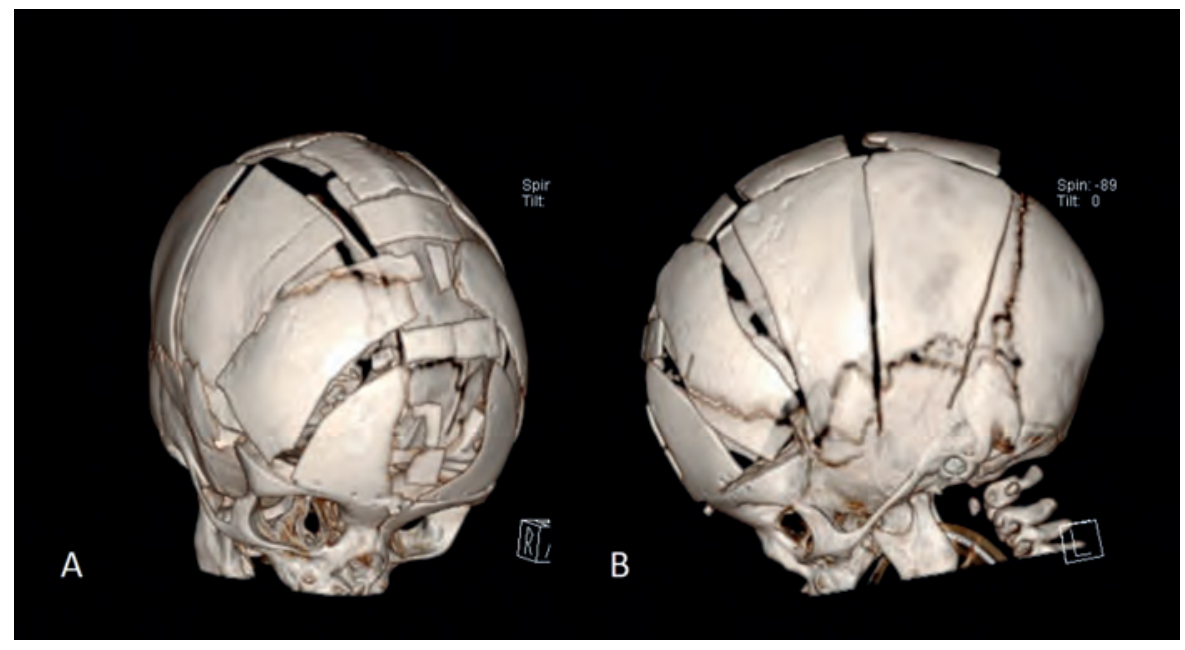

SLIKA 8. CT GLAVE PO REMODELIRANJU LOBANJSKEGA SVODA ZARADI SKAFOCEFALIJE. NE UPORABIMO OSTEOSINTETSKEGA MATERIALA, KER ŽELIMO, DA RASTOČI MOŽGANI SAMI DAJO OBLIKO SPROŠČENI LOBANJI.

FIGURE 8. CT SCAN AFTER SURGICAL REMODELLING FOR SCAPHOCEPHALY. IN THIS SURGICAL PROCEDURE, NO OSTEOSYNTHETIC MATERIAL IS USED TO ALLOW THE GROWING BRAIN TO FREELY RESHAPE THE RELEASED SKULL.

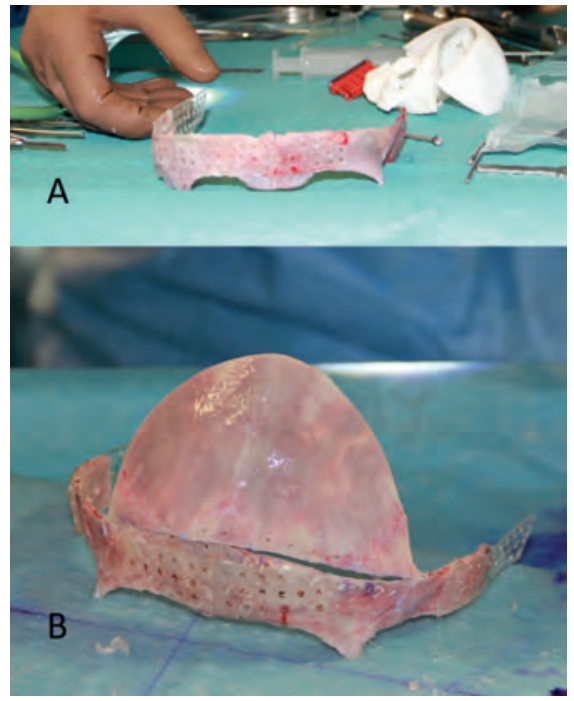

SLIKA 9. S FRONTOORBITALNIM PODALJŠANJEM (FOA) PREOBLIKUJEMO SUPRAORBITALNI LOK (A) IN ČELO (B) TER JU NATO Z OSTEOSINTETSKIM MATERIALOM FIKSIRAMO V NOV, USTREZEN POLOŽAJ.

FIGURE 9. TO CORRECT TRIGONOCEPHALY AND ANTERIOR PLAGIOCEPHALY, ALL THE ANTERIOR PART OF THE CRANIAL VAULT HAS TO BE REMODELLED (A AND B). THIS PROCEDURE IS CALLED FRONTO-ORBITAL ADVANCEMENT (FOA). 


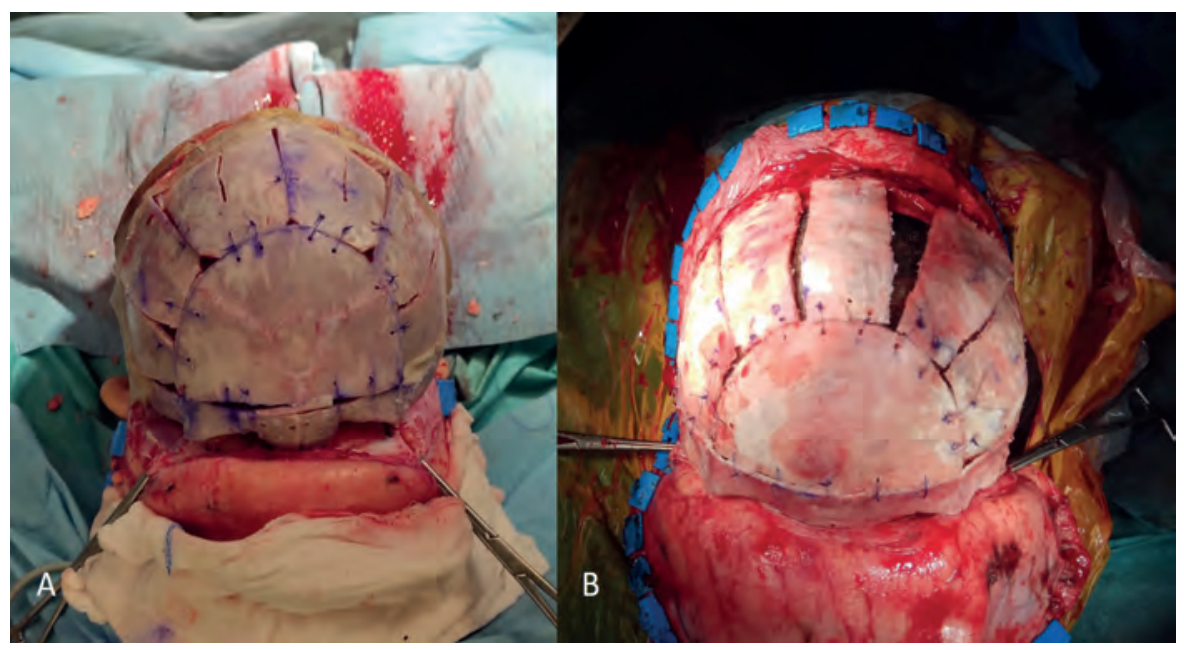

SLIKA 10. ZA KOREKCIJO TRIGONOCEFALIJE IN ANTERIORNE PLAGIOCEFALIJE REMODELIRAMO VES SPREDNJI DEL LOBANJSKEGA SVODA (A IN B). POSEG IMENUJEMO FRONTO-ORBITALNO PODALJŠANJE OZ. REMODELIRANJE (FOA).

FIGURE 10. DURING FRONTO-ORBITAL ADVANCEMENT (FOA), THE SUPRAORBITAL ARCH (A) HAS TO BE REMODELLED TOGETHER WITH THE FOREHEAD (B) AND THEN FIXED IN THE CORRECT POSITION WITH OSTEOSYNTHETIC MATERIAL.

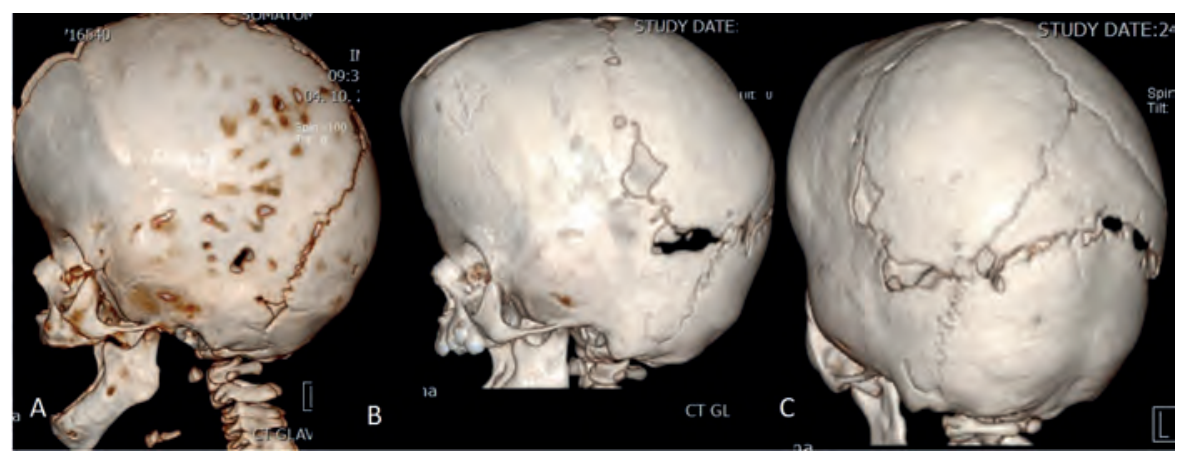

SLIKA 11. STANJE PRED (A) IN PO (B, C) POSTERIORNI OSTEOGENI DISTRAKCIJI. NA SLIKI B IN SLIKI C SO BILI DISTRAKTORJI ŽE ODSTRANJENI, VIDNA JE ŽE DELOMA ZAKOSTENELA LINIJA POSTERIORNE OSTEOTOMIJE, S POMOČJO DISTRAKTORJEV RAZŠIRJENA ZA PRIBLIŽNO $20 \mathrm{MM}$.

FIGURE 11. THE IMAGE SHOWS THE PREOPERATIVE (A) AND POSTOPERATIVE (B AND C) APPEARANCE OF THE SKULL BEFORE AND AFTER POSTERIOR OSTEOGENIC DISTRACTION. IN IMAGES B AND C, THE DISTRACTORS HAVE ALREADY BEEN REMOVED AND A LINE OF NEW BONE DEPOSITION IS SEEN IN THE DISTRACTED OSTEOTOMY LINE, WHICH HAS BEEN ENLARGED BY APPROXIMATELY 20 MM.
Brahicefalija

Korekcija brahicefalije zahteva remodeliranje celotnega lobanjskega svoda, torej frontoorbitalne in okcipitalne regije. To opravimo v dveh fazah, najprej s posteriorno in nato $z$ anteriorno ekspanzijo. Posteriorno ekspanzijo lahko opravimo $z$ remodeliranjem in fiksacijo parietalne in okcipitalne kosti ter posteriorno distrakcijo. Pri tej tehniki na robove parietokcipitalne kraniotomije nastavimo zunanje distraktorje, ki jih en teden po posegu začnemo širiti za $1 \mathrm{~mm}$ na dan. Končni cilj je podaljšanje posteriornega dela lobanje za 25-30 mm (Slika 11). Postopna ekspanzija omogoča, da pri posegu ne pride do prevelike napetosti kožne rane. Približno 3-6 mesecev po zaključeni distrakciji, ko pride do osifikacije dure med robovi kraniotomije, distraktorje odstranimo. Volumen, ki ga pridobimo s posteriorno ekspanzijo, je bistveno večji kot pri anteriorni ekspanziji, zato poseg opravimo pred anteriornim remodeliranjem. V izogib zgodnjemu pojavu povišanega znotrajlobanjskega tlaka se za poseg odločimo zgodaj, običajno med 4. in 8. mesecem starosti.

Po odstranitvi posteriornih distraktorjev moramo opraviti še frontoorbitalno podaljšanje (FOA). Izvedemo ga preko istega kožnega vreza, idealno med drugim in tretjim letom starosti. $S$ posegom želimo ustvariti prostor za rast frontalnih možganskih režnjev in popraviti estetsko deformacijo zaradi previsnega čela.

\section{Posteriorna plagiocefalija}

Pri operaciji posteriorne plagiocefalije moramo opraviti ekspanzijo temporoparietookcipitalne regije na strani kraniosinostotičnega šiva. Poseg idealno opravimo med 6 . in 12. mesecem starosti. Ekspanzijo lahko izvedemo z remodelacijo in fiksacijo kosti ali z enostransko distrakcijo.

\section{Sindromske kraniosinostoze}

Sindromske kraniosinostoze so kompleksni primeri, pri katerih so poleg 
kraniosinostoze prisotne tudi druge nevrološke težave (hidrocefalus, Chiarijeva malformacija, znotrajlobanjska hipertenzija). Prisotne so tudi obstrukcijske apneje, eksoftalmus, sindaktilije in druge malformacije udov $(1,15)$.

Ovire pri rasti lobanje so različne glede na sindrom (Apertov, Pfeifferjev, Crouzonov), zato moramo zdravljenje prilagoditi tem razlikam. Zdravljenje poteka v dveh korakih. Najprej opravimo posteriorno ekspanzijo oz. distrakcijo lobanje za omejitev porasta znotrajlobanjskega tlaka, herniacije tonzil in razvoja turicefalije, idealno med 4. in 8. mesecem starosti. V drugi fazi zdravljenja izvedemo anteriorno ekspanzijo lobanje, ob prisotnosti perifernih obstrukcijskih apnej in izrazitega eksoftalmusa pa je med 12. in 24. mesecem starosti priporočljivo podaljšanje čela in obraza (angl. monobloc advancement). Celoten kostni masiv čela, orbit in obraza podaljšamo in po potrebi povežemo na distraktorje, ki omogočajo postopno skupno podaljšanje in remodeliranje frontalnega in maksilarnega masiva. Ob odsotnosti perifernih apnej lahko poseg opravimo tudi v dveh ločenih delih, sprva s FOA, nato z osteotomijami Lefort 3. Posege Lefort 3 in t. i. monobloc advancement izvajajo le $v$ redkih referenčnih centrih. $V$ UKC Ljubljana jih ne opravljamo, zato redke otroke, ki jih potrebujejo, napotimo na kraniofacilani konzilij UKC Ljubljana v tujino.

Med razvojem moramo pri otrocih redno nadzorovati morebitni pojav znotrajlobanjske hipertenzije in hidrocefalusa s pregledi očesnega ozadja ter radiološkimi preiskavami CT in MRI. V naši seriji bolnikov smo povišan znotrajlobanjski tlak po posegu diagnosticirali v enem samem primeru, pri katerem smo zato postavili indikacijo za nov poseg biparietalne ekspanzije svoda.

Apnejam moramo slediti z rednimi polisomnografijami. $V$ najhujših primerih perifernih obstrukcijskih apnej opravimo traheotomijo že v prvih tednih ali mesecih življenja. Če z nočno polisomnografijo dokažemo prisotnost centralnih apnej in če z MRI potrdimo prisotnost Chiarijeve malfomacije, priporočamo dekompresijo kraniocervikalnega prehoda.

Hidrocefalus v primeru kraniosinostoze poskušamo zdraviti brez vstavitve ventrikulo-peritonealne drenaže $(1,2)$, najprej $z$ ekspanzijo lobanje in kraniocervikalno dekompresijo, ki lahko zmanjšata vensko hipertenzijo in s tem izboljšata resorpcijo likvorja. Če do tega ne pride, opravimo endoskopsko ventrikulostomijo in ventrikuloperitonealno drenažo kot zadnjo možnost, saj drenaža likvorja povzroča znotrajlobanjsko hipotenzijo, ki ovira ugodno pooperativno preoblikovanje lobanje.

\section{Zaključki}

V Enoti za otroško nevrokirurgijo UKC Ljubljana smo v obdobju od junija 2015 do septembra 2020 zdravili 71 otrok s kraniosinostozami. Pojavnost kraniosinostoz v Sloveniji je 1/1500 rojstev in je primerljiva s podatki večjih svetovnih raziskav. Najbolj pogosta je bila kraniosinostoza sagitalnega šiva, sledili sta ji kraniosinostoza metopičnega šiva in enostranska koronarna sinostoza. Manj pogosti sta bili koronarna in lambdoidna kraniosinostoza. Sindromskih kraniosinostoz je bilo $7 \%$.

Obravnava kraniosinostoz je multidisciplinarna. Pomembno je, da jih zgodaj odkrijemo in bolnike pravočasno usmerimo v specializirane centre, kjer je možna celovita obravnava. $V$ Sloveniji primere celovito obravnava multidisciplinarni Kraniofacialni konzilij v UKCL. Otroke z redkimi oblikami sindromskih kraniosinostoz napotimo na zdravljenje v tujino. Kirurško zdravljenje kraniosinostoz zahteva multidisciplinarno znanje nevrokirurgije, maksilofacialne in oralne kirurgije ter plastične in rekonstruktivne kirurgije.
Literatura

1. Cinalli G, Sainte-Rose C, Kollar EM, Zerah M, Brunelle F, Chumas P et al. Hydrocephalus and craniosynostosis. J Neurosurg 1998; 88: 209-14.

2. Arnaud E, Paternoster G, James C, MorisseaU-Durand M-P, Couloigner V, Diner $P$ et al. Stratégie craniofaciale pour les faciocraniosténoses. Ann Chir Plast Esthet 2016; 61: 408-19.

3. Kajdic N, Spazzapan P, Velnar T. Craniosynostosis - Recognition, clinical characteristics, and treatment. Bosn J Basic Med Sci 2018; 18: 110-6.

4. Van der Meulen J. Metopic synostosis. Childs Nerv Syst 2012; 28: 1359-67.

5. Chieffo D, Tamburrini G, Massimi L, Di Giovanni S, Giansanti C, Caldarelli M, Di Rocco C. Long-term neuropsychological development in single-suture craniosynostosis treated early. J Neurosurg Pediatr 2010; 5: 232-7.

6. Van Wijk RM, Pelsma M, Groothuis-Oudshoorn CG, IJzerman MJ, van Vlimmeren LA, Boere -Boonekamp MM. Response to pediatric physical therapy in infants with positional preference and skull deformation. Phys Ther 2014; 94: 1262-71.

7. Esparza J, Hinojosa J, García-Recuero I,

Romance A, Pascual B, Martínez de Aragón A. Surgical treatment of isolated and syndromic craniosynostosis. Results and complications in 283 consecutive cases. Neurocirugia 2008; 19 : 509-29.

8. Ruiz-Correa S, Sze RW, Starr JR, Lin HT, Speltz ML, Cunningham ML et al. New scaphocephaly severity indices of sagittal craniosynostosis: a comparative study with cranial index quantifications. Cleft Palate Craniofac J 2006; 43: 211-21.

9. Magge SN, Westerveld M, Pruzinsky T, Persing JA. Long-term neuropsychological effects of sagittal craniosynostosis on child development. J Craniofac Surg 2002; 13: 99-104.

10. Di Rocco F, Knoll Bl, Arnaud E, Blanot S, Meyer P, Cuttarree H et al. Scaphocephaly correction with retrocoronal and prelambdoid craniotomies (Renier's "H" technique). Childs Nerv Syst 2012; 28: 1327-32

11. Jugović D, Spazzapan P. Endoskopsko zdravljenje skafocefalije. Prikaz primera in nove operacijske tehnike. Zdrav Vestn 2015; 84 : 642-8.

12. Tessier P, Guiot G, Rougerie J, Delbet JP, Pastoriza J. Cranio-naso-orbito-facial osteotomies. Hypertelorism. Ann Chir Plast 1967; 12 103-18.

13. Bottero L, Lajeunie E, Arnaud E, Marchac D, Renier D. Functional outcome after surgery for trigonocephaly. Plast Reconstr Surg 1998; 102 : 952-8.

14. Spazzapan P, Bosnjak R, Velnar T. Craniofacial reconstruction of the skull in anterior plagiocephaly: A case report. Br J Med Med Res 2016; 18: 1-7.

15. Spazzapan P, Arnaud E, Baujat G, Nizon M, Malan V, Brunelle F et al. Clinical and neuroradiological features of the $9 p$ deletion syndrome. Childs Nerv Syst 2016; 32: 327-35. 
asist. Peter Spazzapan, dr. med.

(kontaktna oseba/contact person)

Enota za pediatrično nevrokirurgijo,

Klinični oddelek za nevrokirurgijo,

Univerzitetni klinični center Ljubljana,

Zaloška cesta 7, 1000 Ljubljana, Slovenija

e-pošta: peter.spazzapan@kclj.si

Miha Kočar, dr. dent. med.

Klinični oddelek za maksilofacialno in oralno kirurgijo, Univerzitetni klinični center Ljubljana, Ljubljana, Slovenija

mag. Andreja Eberlinc, dr. med.

Klinični oddelek za maksilofacialno in oralno kirurgijo, Univerzitetni klinični center Ljubljana, Ljubljana, Slovenija

prof. dr. Tomaž Velnar, dr. med. Enota za pediatrično nevrokirurgijo Klinični oddelek za nevrokirurgijo, Univerzitetni klinični center Ljubljana, Ljubljana, Slovenija

prispelo/received: 17. 12. 2020 sprejeto/accepted: 18. 2. 2021

Spazzapan P, Kočar M. Kraniofacialne rekonstrukcije pri otrocih s kraniosinostozo. Slov Pediatr 2021; 28(2): 67-77. https://doi.org/10.38031/ slovpediatr-2021-2-01. 